\title{
GMT BASED COMPARATIVE ANALYSIS AND GEOMORPHOLOGICAL MAPPING OF THE KERMADEC AND TONGA TRENCHES, SOUTHWEST PACIFIC OCEAN
}

\author{
Polina LEMENKOVA ${ }^{1}$
}

DOI: 10.21163/GT_2019.142.04

\begin{abstract}
:
Current study is focused on the GMT based modelling of the two hadal trenches located in southwest Pacific Ocean, eastwards from Australia: Tonga and Kermadec. Due to its inaccessible location, the seafloor of the deep-sea trench can only be visualized using remote sensing tools and advanced algorithms of data analysis. The importance of the developing and technical improving of the innovative methods in cartographic data processing is indisputable. Automatization in data analysis has been significantly increased over the past years. However, using programming and scripting in cartography still remains lower comparing to the use of the traditional GIS. Therefore, developing GMT-based methods for the geomorphological data processing is crucial for better understanding the landforms of the seafloor. Methodology includes application of the GMT scripting toolset for the automated digitizing of the profiles crossing the trenches in perpendicular direction. A sequence of the GMT codes enabled to visualize raster and vector data, perform geomorphological modelling, descriptive statistical data analysis and quantitative comparison of the two trenches. Using GMT, the bathymetric sample data of the Kermadec and Tonga trenches were modeled, analyzed and compared. The results show deeper bathymetry and more seafloor roughness for the Tonga. Comparing to Kermadec, Tonga Trench has steeper gradient of the profiles. The seafloor geomorphology is strongly affected by a variety of factors that shape actual form of both trenches. The experimental methodology is fully based on the GMT scripting with presented and explained codes.
\end{abstract}

Key-words: GMT, geomorphology, mapping, hadal trench, Tonga, Kermadec

\section{INTRODUCTION}

The structure of the ocean seafloor has been the subject of the attention in Earth sciences recently (Micallef, 2011; Mitchell, 2015). The rapidly developing GIS methods, machine learning algorithms and automatization in geospatial analysis improves the precision and quality of the mapping. One of these tools, the Generic Mapping Tools (GMT), a geospatial scripting toolset developed by Wessel \& Smith (1991) provides advanced cartographic solutions that enable to model, analyze, map, visualize and calculate the phenomena of the submarine geology that can only be studied by the remote sensing methods and complex algorithms of data analysis. A variety of the GMT modules (Wessel et al, 2013) specifically adjusted for modelling raster grids, plotting vector maps, computing descriptive statistical graphs and aesthetic cartographic mapping proved to be a perfect tool for modelling oceanological data. Current work is fully based on using GMT for comparative analysis and geomorphic modelling of two hadal trenches.

The presented research is focused on the comparative analysis and geomorphological modelling of the two hadal trenches located in the Pacific Ocean: Kermadec and Tonga

1 Ocean University of China, College of Marine Geo-sciences, 266100, Qingdao, Shandong

Province, China, pauline.lemenkova@gmail.com or lemenkovapolina@stu.ouc.edu.cn; 
(Fig. 1). Using GMT modelling, the shapes of their orthogonal transect profiles were compared and analyzed in order to highlight differences and variations in the landforms of the two trenches located close to each other yet different in structure. The majority of research either focus on the biota communities of the deep-sea ecosystems (Leduc, 2015; Nunnally et al., 2016; Leduc et al, 2016) or the tectonic movements of the plates in the Pacific Ocean (Duncan et al., 1985; Tappin, 1993; Piller et al., 1999). The presented work aims to contribute to the studies on the geomorphological modelling of the hadal trenches of the Pacific Ocean.

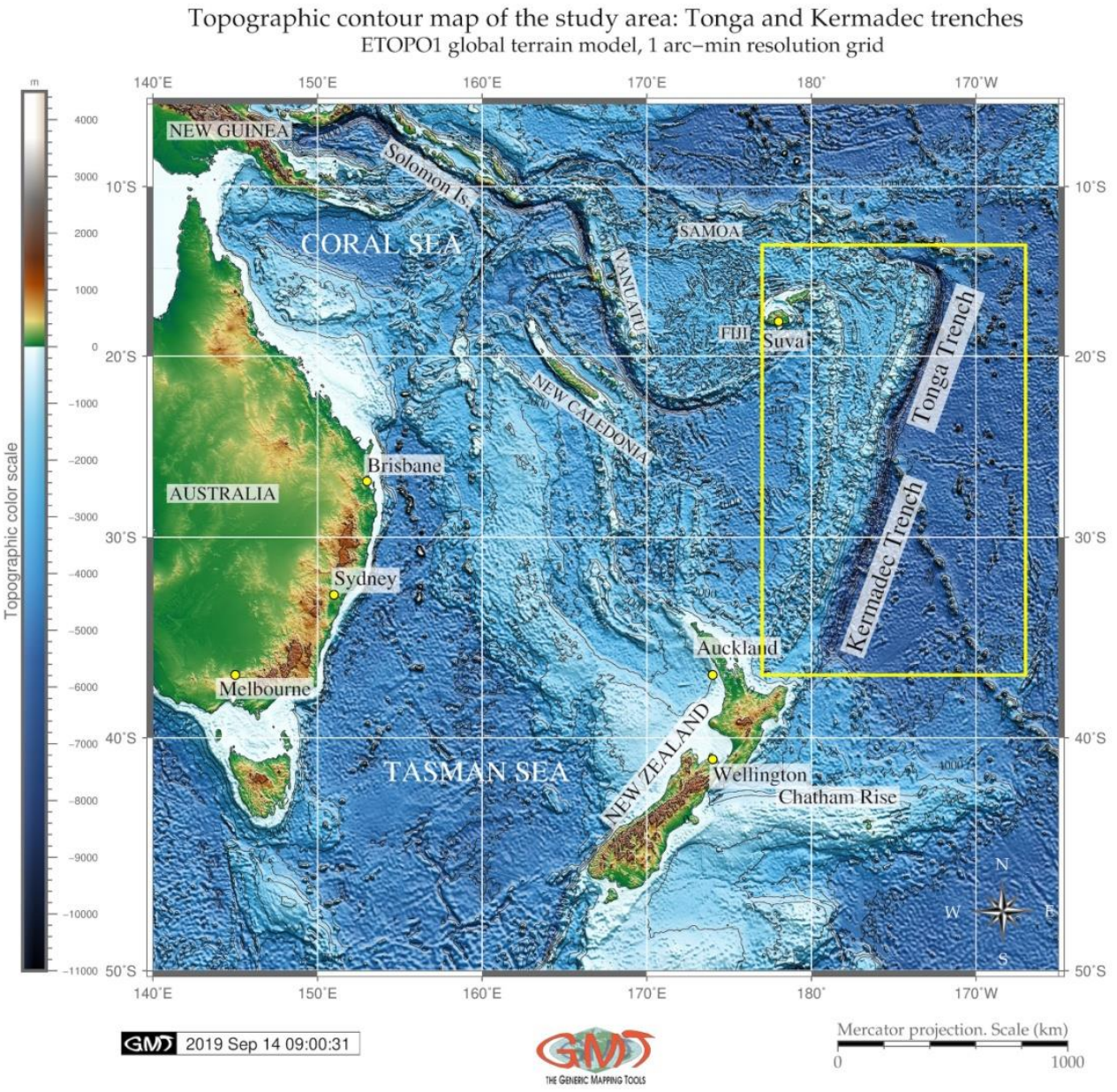

Fig. 1. Map of the study area: Kermadec and Tonga trenches, Pacific Ocean (Source: author).

\section{STUDY AREA AND DATA}

The study area is focused on two hadal trenches located in south-west Pacific Ocean northwards from Australia and New Zealand: Kermadec and Tonga. Their brief geographic description can be characterized as follows. Kermadec Trench is the southern from the two located $120 \mathrm{~km}$ off the New Zealand with axis continuing from ca. $26^{\circ} \mathrm{S}$ to $36^{\circ} \mathrm{S}$. It is the $5^{\text {th }}$ deepest trench in the world with a maximum depth of 10,177 $\mathrm{m}$ (Jamieson, 2015) $\mathrm{m}$ and a 
length of $1500 \mathrm{~km}$ (Jamieson et al, 2011). Its closeness to the Antarctic makes it one of the coldest trenches in the world (Belyaev, 1989).

Kermadec Trench runs parallel to the Kermadec Ridge with geomorphology of V-shape formed by tectonic subduction of the Pacific Plate under the Indo-Australian Plate extending from approximately $26^{\circ}$ to $36^{\circ} \mathrm{S}$ near the northeastern tip of New Zealand's North Island (Leduc \& Rowden, 2018).
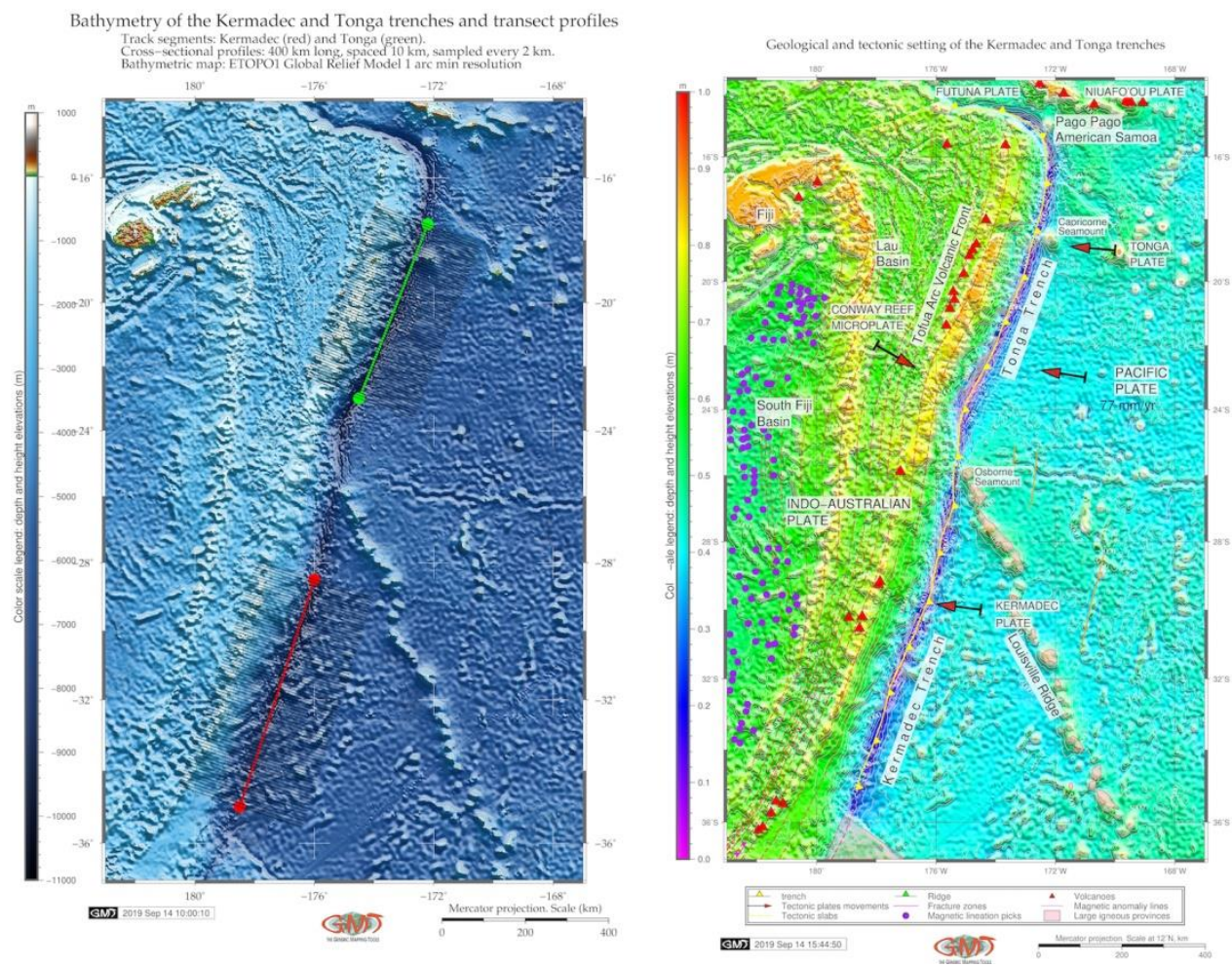

Fig. 2. Transect segments of the cross-secton profiles in Kermadec and Tonga trenches (left). Geologic and tectonic settings of the trenches (right) (Source: author).

The specific conditions of the tectonic setting in the study area is the subduction of the Pacific Plate at a rapid rate beneath the Indo-Australian Plate along the Tonga-Kermadec Trench (Castillo et al., 2009), Fig. 2, right. Specifically, a convergence at maximal rate $249 \mathrm{~mm} / \mathrm{yr}$ ) along the Tonga-Kermadec arc system makes it one of the most seismically active subduction zones in the world (Bevis et al., 1995). Due to the complex interaction of various factors (ocean currents, closeness to the Antarctica) the deep Pacific Ocean seafloor underlying the trenches is notable for variable surface productivity (Linley et al, 2017). Detailed description of the environmental, geological and tectonic settings of the Kermadec is in Smith et al. (2003); Anderson, 2006; Regelous et al., 1997; Smith \& Price, 2006.

Tonga Trench is adjacent, continuing Kermadec Trench northwards with axis stretching from ca. $15^{\circ} \mathrm{S}$ to $26^{\circ} \mathrm{S}$. Located in close proximity to the Kermadec, it is separated by a sill located on the Tonga Platform (Wright et al., 2000) and by the Louisville Seamount Chain 
(Jamieson et al, 2013) (Fig. 2, right). With maximum depths of 10,882 $\mathrm{m}$, the Tonga Trenches is the $2^{\text {nd }}$ deepest trench in the world (Blankenship et al, 2006). Similar to the Kermadec, Tonga Trench belongs to the South Pacific Subtropical Gyre (SPSG) biogeochemical province and has the same primary productivity rate rate of $87 \mathrm{~g} \mathrm{C} \mathrm{m}-2$ $\mathrm{y}-1$ (Xu et al, 2018). Both trench axes have roughly $30^{\circ}$ slight from the longitude line. Further studies on Tonga Trench, its environment and communities can be found in relevant literature (Tappin, 1993; Ewart et al., 1993; Hergt \& Woodhead, 2007).

\section{METHODOLOGY}

\subsection{GMT codes for the topographic and geological mapping}

A methodological approach consists in the sequence of the GMT modules. Each module consists of the small code line. Combined together as a script, they are used for mapping. Thus, the following GMT modules were used to map Fig. 1:

gmt grdcut earth_relief_01m.grd -R140/195/-50/-5 -Gtkt_relief.nc -V

Here the necessary part of the image was cut off and the coordinates were given (R140/195/-50/-5) in WESN way. The raster data used as a basis map is ETOPO1. The coordinates in southern hemisphere are given as negative values. The module 'grdinfo' was used to analyze the output raster (tkt_relief.nc):

gmt grdinfo @ tkt_relief.nc

The color palette was made using 'makecpt' module from the available 'geo' palette adjusted according to the data range (topography from -11000 to 4500):

gmt makecpt -Cgeo.cpt -V -T-11000/4500 > myocean.cpt

Following that the raster image was visualized:

gmt grdimage earth_relief_01m.grd -Cmyocean .cpt \

-R140/195/-50/-5 -JM6i -P -I+a15+ne0.75 -Xc -K > \$ps

Here the '-JM6i' means Mercator projection with 6 inches width of the map; '-P' means portrait orientation; '-K' means continue of the script (not finalized).

The legend was added using 'psscale' module using the following code snippet:

gmt psscale -Dg131/-50+w14.8c/0.4c+v+o0.3/0i+ml Rtkt_relief.nc -J -Cmyocean.cpt -FONT_LABEL=8p,Helvetica,dimgray

FONT_ANNOT_PRIMARY=5p,Helvetica,dimgray -Baf+1"Topographic color scale" -I0.2 $-\mathrm{By}+\mathrm{lm}-\mathrm{O}-\mathrm{K}>>$ ps

\subsection{GMT codes for the geological mapping of the study area}

The geological layers (lines and points) were added on Fig. 2 (right) using the following code snippet. As can be seen (the code below), the plotting of the vector elements on the map is done using '-W' command, e.g. '-Wthinnest,red'.

Each code is saved to the initially created file using $\gg$ ps command. The first mention of this command goes with single bracket, e.g. '> \$ps'. Then all the elements that are added to the map overlay the same. In this sense, there is certain similarity with GIS layers and a sequence of codes in the whole GMT script. The initial files with extension gmt (e.g. ridge.gmt) are tables with attribute data (coordinates and values) in native GMT format.

Hence, the following code was used for geological mapping on Fig. 2, right:

gmt makecpt -Crainbow -T0/700/50 -Z > rain.cpt

gmt psxy -R -J volcanoes.gmt -St0.4c -Gred -Wthinnest -O -K >> \$ps

gmt psxy -R -J ridge.gmt $-\mathrm{Sf0} 0.5 \mathrm{c} / 0.2 \mathrm{c}+\mathrm{l}+\mathrm{t}-\mathrm{W}$ thinnest, black -Ggreen $-\mathrm{O}-\mathrm{K}>>$ ps

gmt psxy -R -J LIPS.2011.gmt -L -Gpink1@50 -Wthinnest,red -O -K >> \$ps 
\# Adding slab contours and magnetic lineation picks gmt psxy -R -J SC_tonga.txt -W0.6p,red,- -O -K >> \$ps

gmt psxy -R -J GSFML.global.picks.gmt -Sc0.2c -Wthin,purple -Gpurple -O -K >> \$ps gmt psxy -R -J trench.gmt $-\mathrm{Sf} 1.5 \mathrm{c} / 0.2 \mathrm{c}+\mathrm{l}+\mathrm{t}-\mathrm{W}$ thick, yellow -Gyellow $-\mathrm{O}-\mathrm{K}>>$ ps
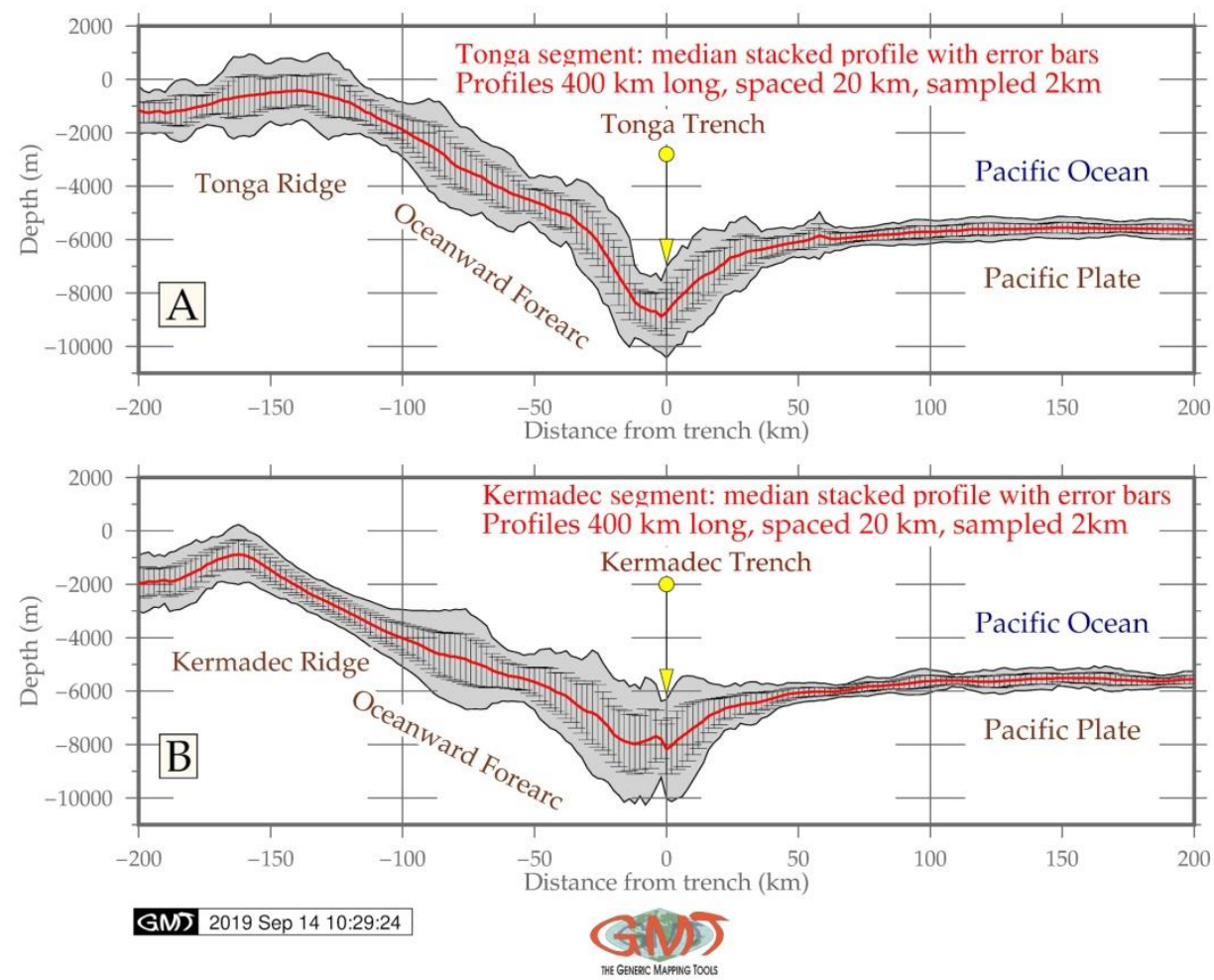

Fig. 3. Geomorphological modelling of the trenches by GMT (Source: author).

The GMT module 'psxy' was used for adding annotations on the maps, plotting geologic lineaments and sample points. The 'psbasemap' and 'grdcontour' GMT modules were used to map base map elements: bathymetry contours, net grids, titles and subtitles.

\subsection{GMT codes for the geomorphological modelling of the cross-section profiles}

The combination of several GMT modules was used for mapping geomorphological profiles (Fig. 2, left). The modelling was done using following code (example for the Kermadec Trench). The trench segment and end points were plotted:

gmt psxy -Rtkt_relief.nc -J -W2p,red trenchK.txt -O -K > \$ps \# my line gmt psxy -R -J -Sc0.15i -Gred trenchK.txt $-\mathrm{O}-\mathrm{K}>>$ ps \# points

Then, the profiles $400 \mathrm{~km}$ long, spaced $10 \mathrm{~km}$, sampled every $2 \mathrm{~km}$ were generated using 'grdtrack' GMT module based on the 'tkt_relief.nc' raster in NetCDF format:

gmt grdtrack trenchK.txt -Gtkt_relief.nc $-\mathrm{C} 400 \mathrm{k} / 2 \mathrm{k} / 10 \mathrm{k}+\mathrm{v} \quad-\mathrm{Sm}+$ sstackK.txt > tableK.txt

The profiles were written into table: gmt psxy -R -J -W0.5p tableK.txt -O -K > \$ps

The modelling of the profiles was performed by the following code snippet: 
gmt psxy -R-200/200/-11000/2000 -JX15.2c/5c -Bxag100f50+1"Distance from trench (km)" -Byag2000f1000a2000+l"Depth (m)" -BWeSn \

-Glightgray -W0.5p envK.txt -UBL/-2p/-45p -K > \$ps

gmt psxy -R -J -W1.0p -Ey+p0.2p stackK.txt -O -K > \$ps

gmt psxy $-\mathrm{R}-\mathrm{J}-\mathrm{W} 1 \mathrm{p}$, red stackK.txt $-\mathrm{O}-\mathrm{K}>>$ ps

The annotations were added using Unix utility 'echo', for example:

echo "-70 -100 Profiles $400 \mathrm{~km}$ long, spaced $20 \mathrm{~km}$, sampled 2km" | gmt pstext -R -J Gwhite $-\mathrm{F}+\mathrm{jBL}+\mathrm{f} 12 \mathrm{p}$,red $-\mathrm{O}-\mathrm{K}>>$ ps

Final visualization is presented on Fig. 3.
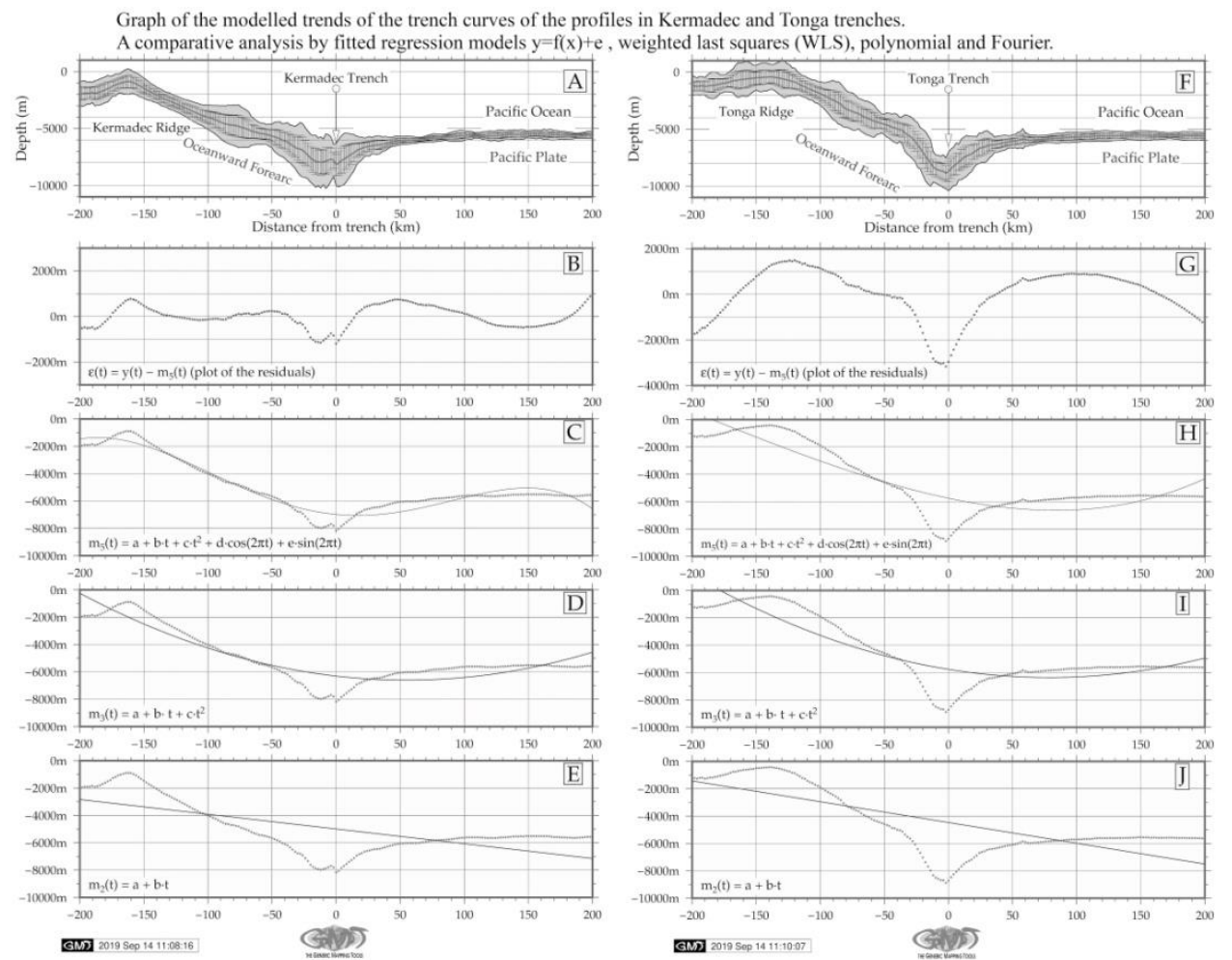

Fig. 4. Mathematical approximation of the trend curves of the profiles (Source: author).

\subsection{GMT codes for the mathematical approximation of the trends and histograms}

A sequence of the codes was applied to model trends visualized on Fig. 4 by modules: For example, basic LS line shown on the Fig. 4, E (lower left), $y=a+b x+c x^{\wedge} 2$ was plotted using following methodology combining GMT and Unix utilities:

gmt trend1d -Fxm stackK.txt -Np2 > model.txt gmt psxy -R -J -Bpxag100f10 -Bsxg50 -Bpyaf+u"m" -Bsyg2000 \

-BWSne+gazure 1 -Sc0.05c-Gred stackK.txt -Y5.0c -O -K > \$ps gmt psxy -R -J -W0.5p,blue model.txt $-\mathrm{O}-\mathrm{K}>>$ \$ps echo "m@-3@-(t)=a + b\267 t +cl267t@+2@+" | gmt pstext -R -J

$-\mathrm{F}+\mathrm{f} 11 \mathrm{p}+\mathrm{cBL}-\mathrm{Dj} 0.1 \mathrm{i}-\mathrm{Glightyellow}-\mathrm{O}-\mathrm{K}>>\mathrm{ps}$ 


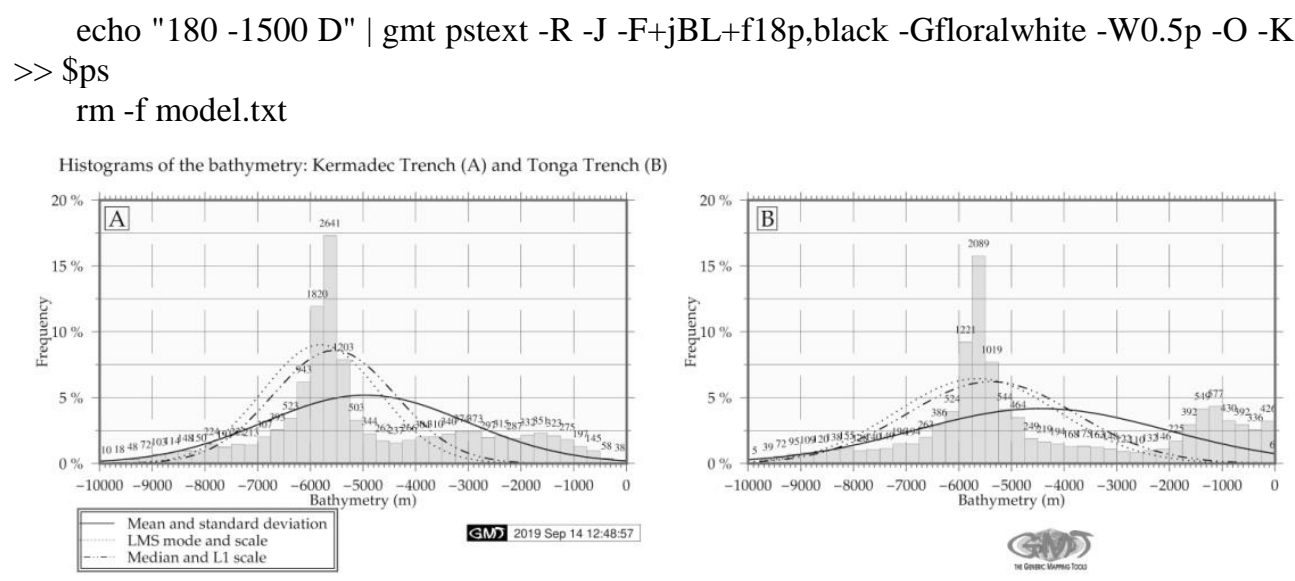

Fig. 5. Histograms of the bathymetry: frequency of the distribution of depths by data for both trenches. Left: Kermadec, right: Tonga (Source: author).

The same procedure was repeated for several mathematic approximations of the trend lines showing general profile shapes and gradients for both trenches. The comparison of trenches was computed using module 'pshistogram' (Fig. 5) by following code:

gmt pshistogram tableK.txt -i4 -R-10000/6/0/20 -JX4.8i/2.4i ।

-Bpxg1000a1000f100+l"Bathymetry (m)" ।

-Bpyg5a5f2.5+l"Frequency"+u" \%" -Bsyg2.5

-BWSne+t"Histograms of the bathymetry: Kermadec Trench (A) and Tonga Trench (B)"+gsnow1 -Glightsteelblue1 \

-D+f7p,Times-Roman,black -L0.1p,dimgray -Z1 -W250 -N0+pblack -N1+p..- $\mathrm{N} 2+\mathrm{p} .1$

$-\mathrm{UBL} / 8.5 \mathrm{c} /-1.8 \mathrm{c}-\mathrm{K}>\$ \mathrm{ps}$

\section{RESULTS AND DISCUSSIONS}

The resulting profiles are visualized as two segments (red and green for both trenches) on Fig. 2, left. Automatic digitizing of the cross-section profiles for Kermadec and Tonga trenches demonstrated that Tonga trench's geomorphology has steeper gradient slope on the western flank (Fig. 3, A). On the contrary, Kermadec trench (Fig. 3, B) has more gentle shape form of the western slope off Tonga Ridge. The results of the comparative analysis of the two trenches show that Tonga Trench has shallower depths on the eastern part along but kermadec Trench has more abrupt shape with 2,641 depth records s from $-6,600$ to $-6,800$ meters (Fig. 5). Comparing the deepest values $>9,000$ meters for Tonga Trench there are 5, 39, 72, 95, 109 observations, that sums together 320 samples. As for kermadec Trench for the same depth range there are 10, 18, 48, 72 and 103, which gives together 251 observation samples proving that Tonga Trench is deeper than Kermadec Trench.

If we compare the variations of the seafloor depths at range from $-6,000$ to $-5,000$, it can be sen (Fig. 5) that Kermadec Trench has more values in this range: 1820, 2641, 1203 and 503 giving together 6167 samples. For the Tonga Trench, the same range gives 4803 (a sum of 1221, 2089, 1019 and 544). That means that Kermadec has more gentle slope and 
shallower depths which can also be seen on Fig. 3. This illustrates tectonic and geological local variations, as well as different sedimentation of the Kermadec and Tonga trenches causing variations in their geomorphic shape despite their close location to each other.

\section{CONCLUSIONS}

Various factors affect formation, functioning and sustainability of the marine habitats and hadal trenches as one of the unique places of the oceans, as discussed in previous papers (Lemenkova, 2018a; Pollnac et al., 2001; Pelletier. \& Louat, 1989; Lemenkova, 2018b). The complex analysis of the structure of the ocean ecosystem based on the advanced data analysis, software and scripting tools significantly increases the precision and speed of the data processing and reliability of the results. Examples of the application of programming languages and statistical tools specifically for the oceanological data modelling were presented in previous publications: Python (Yu et al., 2019; Lemenkova, 2019c; Lemenkova, 2019d), R (Lemenkova, 2019a; Lemenkova, 2019b), SPSS (Lemenkova, 2019f), Gretl (Lemenkova, 2019e). Using GMT advanced scripting toolset for the cartographic modelling increases automatization of the mapping routine. Therefore, GMT is strongly recommended for the geospatial data analysis and thematic mapping.

There are both theoretical and practical innovations of the presented research that can be applied in the similar works. The theoretical novelty lies in the comparative geomorphological mapping of the two hadal trenches that does not exists in the available literature. The practical novelty consists in the developed methodology of the GMT-based mapping rather than traditional GIS, applied for the geomorphic modelling. Tested, presented and explained functionality of the several GMT modules enables to do automated digitizing of the orthogonal profiles crossing trenches in the perpendicular direction. Through this modelling, the shape of the landforms and steepness gradient of the trenches were visualized, compared and statistically analyzed. The traditional handmade cartographic digitizing is a tedious routine usually prone to minor or major errors. On the contrary, using GMT based machine learning for the automatization of the cartographic techniques significantly improves the quality and precision of the modelling.

\section{ACKNOWLEDGEMENTS}

This research was funded by the China Scholarship Council (CSC), State Oceanic Administration, Marine Scholarship of China, Grant Nr. 2016SOA002, Beijing, China.

\section{R E F E R E N C E S}

Anderson, M. E. (2006) Studies on the Zoarcidae (Teleostei: perciformes) of the Southern Hemisphere. XI. A new species of Pyrolycus from the Kermadec Ridge. Journal of the Royal Society of New Zealand, 36, 63-68. doi: 10.3853/j.0067-1975.46.1994.9.

Belyaev, G. M. (1989) Deep-Sea Ocean Trenches and Their Fauna. Nauka Publishing House.

Bevis, M., Taylor, F. W., Schutz, B. E., Recy, J., Isacks, B. L., Helu, S., Singh, R., Kendrick, E., Stowell, J., Taylor, B., Calmant, S. (1995) Geodetic observations of very rapid convergence and back-arc extension at the Tonga arc. Nature 347, 249-251.

Blankenship, L. E., Yayanos, A. A., Cadien, D. B. \& Levin, L. A. (2006) Vertical zonation patterns of scavenging amphipods from the Hadal zone of the Tonga and Kermadec Trenches. Deep-Sea Research I, 53, 48-61. doi: 10.1016/j.dsr.2005.09.006 
Castillo, P. R., Lonsdale, P. F., Moran, C. L. \& Hawkins, J. W. (2009) Geochemistry of midCretaceous Pacific crust being subducted along the Tonga-Kermadec Trench: Implications for the generation of arc lavas. Lithos, 112, 87-102. doi:10.1016/j.lithos.2009.03.041

Duncan, R. A., Vallier, T. L. \& Falvey, D. A. (1985) Volcanic episodes at 'Eua, Tonga Islands. In: Scholl, D.W., Vallier, T.L. (Eds.), Geology and Offshore Resources of Pacific Island Arcs; Tonga Region. Circum-Pac. Counc. Energy and Miner. Resour., Houston, TX, United States, 281-290.

Ewart, A., Collerson, K. D., Regelous, M., Wendt, J. I. \& Niu, Y. (1998) Geochemical evolution within the Tonga-Kermadec Lau arc back- arc systems: the role of varying mantle wedge composition in space and time. Journal of Petrology, 39 (3), 331-368. doi: 10.1093/petroj/39.3.331

Hergt, J. M. \& Woodhead, J. D. (2007) A critical evaluation of recent models for Lau-Tonga arcbackarc basin magmatic evolution. Chemical Geology, 245, 9-44. doi: 10.1016/j.chemgeo.2007.07.022

Jamieson, A. J., Kilgallen, N. M., Rowden, A. A.,Fujii, T., Horton, T., Lörz, A.-N., Kitazawa, K. \& Priede, I. G. (2011) Bait-attending fauna of the Kermadec Trench, SW Pacific Ocean: Evidence for an ecotone across the abyssal-hadal transition zone. Deep-Sea Research I, 58, 49-62. doi: 10.1016/j.dsr.2010.11.003

Jamieson, A. J., Lacey, N. C., Lörz, A.-N., Rowden, A. A. \& Piertney, S. B. (2013) The supergiant amphipod Alicella gigantea (Crustacea: Alicellidae) from hadal depths in the Kermadec Trench. SW Pac. Ocean. Deep-Sea Research Part II Topical Studies in Oceanography, 92, 107-113. doi: 10.1016/j.dsr2.2012.12.00

Jamieson, A. J. (2015) The hadal zone: life in the deepest oceans. Cambridge University Press, Cambridge.

Leduc, D. \& Rowden, A. A. (2018) Nematode communities in sediments of the Kermadec Trench, Southwest Pacific Ocean. Deep-Sea Research Part I, 134, 23-31. doi: 10.1016/j.dsr.2018.03.003

Leduc, D. (2015) New species of Thelonema, Metasphaerolaimus, and Monhystrella (Nematoda, Monhysterida) from Kermadec Trench, Southwest Pacific. European Journal of Taxonomy, 158, 1-19. doi: 10.5852/ejt.2015.158

Leduc, D., Rowden, A. A., Glud, R. N., Wenzhöfer, F., Kitazato, H. \& Clark, M. R. (2016) Comparison between infaunal communities of the deep floor and edge of the Tonga Trench: possible effects of differences in organic matter supply. Deep-Sea Research Part I Oceanographic Research Papers, 116, 264-275. doi: 10.1016/j.dsr.2015.11.003

Lemenkova, P. (2019a) Statistical Analysis of the Mariana Trench Geomorphology Using R Programming Language. Geodesy and Cartography, 45 (2), 57-84. ISSN: 2029-6991. doi: 10.3846/gac.2019.3785

Lemenkova, P. (2019b) An Empirical Study of R Applications for Data Analysis in Marine Geology. Marine Science and Technology Bulletin, 8(1), 1-9. doi: 10.33714/masteb.486678

Lemenkova, P. (2019c) Processing oceanographic data by Python libraries NumPy, SciPy and Pandas, Aquatic Research, 2, 73-91, doi: 10.3153/AR19009

Lemenkova, P. (2019d) Testing Linear Regressions by StatsModel Library of Python for Oceanological Data Interpretation. Aquatic Sciences and Engineering, 34, 51-60, doi: 10.26650/ASE2019547010

Lemenkova, P. (2019e) Regression Models by Gretl and R Statistical Packages for Data Analysis in Marine Geology. International Journal of Environmental Trends, 3(1), 39-59, doi: 10.6084/m9.figshare.8313362.v1

Lemenkova, P. (2019f) Numerical Data Modelling and Classification in Marine Geology by the SPSS Statistics. International Journal of Engineering Technologies, 5(2), 90-99. doi: 10.6084/m9.figshare.8796941 
Lemenkova, P. (2018a) R scripting libraries for comparative analysis of the correlation methods to identify factors affecting Mariana Trench formation. Journal of Marine Technology and Environment, 2, 35-42, doi: 10.6084/m9.figshare.7434167

Lemenkova, P. (2018b) Factor Analysis by R Programming to Assess Variability Among Environmental Determinants of the Mariana Trench. Turkish Journal of Maritime and Marine Sciences, 4, 146-155, doi: 10.6084/m9.figshare.7358207

Linley, T. D., Stewart, A. L., McMillan, P. J., Clark, M. R., Gerringer, M. E., Drazen, J. C., Fujii, T. \& Jamieson, A. J. (2017) Bait attending fishes of the abyssal zone and hadal boundary: Community structure, functional groups and species distribution in the Kermadec, New Hebrides and Mariana trenches. Deep-Sea Research Part I, 121, 38-53. doi: 10.1016/j.dsr.2016.12.009

Micallef, A. (2011) Developments in Earth Surface Processes. Developments in Earth Surface Processes. Chapter 13 - Marine Geomorphology: Geomorphological Mapping and the Study of Submarine Landslides, 15, 377-395. doi: 10.1016/B978-0-444-53446-0.00013-6

Mitchell, N. C. (2015) Submarine Geomorphology. Reference Module in Earth Systems and Environmental Sciences. doi: 10.1016/B978-0-12-409548-9.09249-6

Nunnally, C. C., Friedman, J. R. \& Drazen, J. C. (2016) In situ respiration measurements of megafauna in the Kermadec trench. Deep-Sea Research Part I, 118, 30-36. doi: 10.1016/j.dsr.2016.10.009

Pelletier, B. \& Louat, R. (1989) Seismotectonics and present-day relative plate motions in the TongaLau and Kermadec-Havre region. Tectonophysics, 165, 237-250. doi: 10.1016/00401951(89)90049-8

Pollnac, R. B., Crawford, B. R. \& Gorospe, M. L. (2001) Discovering factors that influence the success of community-based marine protected areas in the Visayas, Philippines. Ocean and Coastal Management, 44(11), 683-710. doi: 10.1016/S0964-5691(01)00075-8.

Regelous, M., Collerson, K. D., Ewart, A. \& Wendt, J. I. (1997) Trace element transport rates in subduction zones: evidence from $\mathrm{Th}, \mathrm{Sr}$ and $\mathrm{Pb}$ isotope data for Tonga-Kermadec arc lavas. Earth and Planetary Science Letters, 150, 291-302. doi: 10.1016/S0012-821X(97)00107-6

Smith, I. E. M. \& Price, R. C. (2006) The Tonga-Kermadec arc and Havre-Lau back-arc system: their role in the development of tectonic and magmatic models for the western Pacific. Journal of Volcanology and Geothermal Research, 156, 315-331. doi: 10.1016/j.jvolgeores.2006.03.006

Smith, I. E. M., Worthington, T. J., Stewart, R. B., Price, R. C., Richard, C. \& Gamble, J. A. (2003) Felsic volcanism in the Kermadec Arc, SW Pacific; crustal recycling in an oceanic setting. Geological Society Special Publications, 219, 99-118.

Tappin, D. R. (1993) The Tonga frontal arc basin. In: Ballance, P.F. (Ed.), Sedimentary Basins of the World: South Pacific Sedimentary Basins, 2. Elsevier, Amsterdam.

Wessel, P. \& Smith, W. H. F. (1991) Free software helps map and display data. EOS Transactions of the American Geophysical Union 72 (41), 441.

Wessel, P., Smith, W. H. F. Scharroo, R., Luis, J. F. \& Wobbe, F. (2013) Generic mapping tools: Improved version released, EOS Transactions of the American Geophysical Union 94(45), 409410, doi:10.1002/2013EO450001

Wright, D. J., Bloomer, S. H., MacLeod, C. J., Taylor, B. \& Goodlife, A. M. (2000) Bathymetry of the Tonga Trench and Forearc: a map series. Marine Geophysical Researches 21, 489-511.

Xu, Y., Ge, H. \& Fang, J. (2018) Biogeochemistry of hadal trenches: Recent developments and future perspectives. Deep-Sea Research Part II, 155, 19-26. doi: 10.1016/j.dsr2.2018.10.006

Yu, Q.-Y., Bagas, L., Yang, P.-H. \& Zhang, D. (2019) GeoPyTool: A cross-platform software solution for common geological calculations and plots. Geoscience Frontiers, 10(4), 1437-1447. 